\title{
Observations beneath Pine Island Glacier West Antarctica and implications for its retreat
}

Adrian Jenkins ${ }^{1}$, Pierre Dutrieux ${ }^{1}$, Stanley S. Jacobs ${ }^{2}$, Stephen D. McPhail ${ }^{3}$, James R. Perrett ${ }^{3}$, Andrew T. Webb ${ }^{3}$, David White ${ }^{3}$

${ }^{1}$ British Antarctic Survey, Natural Environment Research Council, Cambridge, UK.

${ }^{2}$ Lamont-Doherty Earth Observatory of Columbia University, New York, USA.

${ }^{3}$ National Oceanography Centre, Southampton, UK.

Thinning ice in West Antarctica, resulting from acceleration in the flow of outlet glaciers, is currently contributing about $10 \%$ of the observed rise in global sea level $^{1}$. Pine Island Glacier (PIG) in particular has shown nearly continuous acceleration $^{2,3}$ and thinning ${ }^{4,5}$ throughout the short observational record. Rapid thinning of the floating ice shelf ${ }^{6}$ that forms where the glacier reaches the coast, driven by changes in ocean heat transport beneath it, and the consequent inland retreat of the line separating grounded and floating ice ${ }^{7}$ has been postulated to be the cause $\mathrm{e}^{8,9}$. Here we report evidence gathered by an Autonomous Underwater Vehicle (AUV) operating beneath the ice shelf, that PIG was recently grounded on a transverse ridge in the sea floor. Warm seawater now flows through a widening gap above the submarine ridge, rapidly melting the thick ice of the newly-formed upstream half of the ice shelf. The present evolution of PIG is thus part of a longer-term trend that has moved the downstream limit of grounded ice inland by $30 \mathrm{~km}$ into water that is $300 \mathrm{~m}$ deeper than over the ridge crest. The pace and ultimate extent of such a potentially unstable retreat ${ }^{10}$ are central to the debate over the possibility of widespread ice sheet collapse triggered by climate change $^{11,12}$. 
Oceanic influence on the Amundsen Sea ice shelves (Fig. 1a) is determined by the properties and circulation of the Circumpolar Deep Water (CDW) that floods the network of deep, glacially-carved troughs on its continental shelf $f^{13,14}$. CDW is ubiquitous beneath the near-freezing surface waters and permanent thermocline, which occupy the upper $400-600 \mathrm{~m}^{15,16}$, and at $1^{\circ} \mathrm{C}$ it is $3-4^{\circ} \mathrm{C}$ warmer than the freezing point in situ. Upper water column properties at the PIG front are a product of mixing between CDW and meltwater ${ }^{16,17}$, indicating that the CDW flowing into the cavity is responsible for the high melt rates ${ }^{6,7,15,18}$, but leaving unanswered critical questions about the delivery of ocean heat to the base of the floating ice, especially near the deep grounding line. Understanding the processes that determine the melt rate, its distribution and its sensitivity to external forcing requires knowledge of the shape of the sub-ice cavity and the distribution of water properties within it. Furthermore, knowledge of the seabed topography beneath the ice shelf is critical for understanding motion of the grounding line, which separates grounded from floating ice. Glaciological theory suggests that grounding line retreat into deeper water is unstable ${ }^{10}$ and will continue inland until either halted by the next rise in the glacier bed or stabilised by complexities in the glacier flow ${ }^{10,19,20}$. Acquiring the data necessary to understand these processes was the main motivation for deploying the Autosub3 AUV on six missions (Fig 1b) totalling 510 km of track and 94 hours beneath the PIG ice shelf in late January 2009.

Seabed profiles in the outer $25 \mathrm{~km}$ of the cavity were similar along all six AUV tracks, revealing a continuous ridge mid-way between ice front and grounding line (Fig. 2a). The ridge has an undulating crest about $700 \mathrm{~m}$ below sea level and extends southward from Evans Knoll, the most south-westerly outcrop of the Hudson Mountains. Both the ridge and the outer cavity are deepest along the track of missions 428 and 434 (Fig. 1b) and shallower to the north. The highest point encountered on the ridge was less that $650 \mathrm{~m}$ below sea level at the inland limit of mission 433 (Fig. 1b), where shallowing of the sea floor reduced the gap beneath the ice to less than the 
AUV's safe operating limit of $200 \mathrm{~m}$. Water column thickness beneath the ice ranges from 400-600 $\mathrm{m}$ in the outer cavity to less than $250 \mathrm{~m}$ along the ridge crest (Fig. 2b). Inner cavity measurements are restricted to the track of mission 431, where on the inland side of the ridge the water column first thickens then tapers towards the grounding line (Fig. 2c).

Multi-beam acoustic imagery of the sea floor under PIG (Fig.3) revealed bedforms indicating that the ridge was a former grounding line, with sediment scoured from its crest having been deposited on its seaward slope. Bottom roughness in the outer cavity signifies bedrock with a thin or absent sediment drape, matching bedforms mapped from ship-based observations in Pine Island Bay ${ }^{21}$. The outer slope of the ridge is smoother, indicating a thicker sediment cover derived from the ridge crest. Lineations parallel to the present ice flow direction with 10-20 m relief and a wavelength of 0.5-1 km across the ridge crest are clear markings of grounded ice flow in the past. While the ridge could be a sediment wedge formed during a period of grounding line stability, or a moraine produced by a transitory advance, its scale, undulating crest and association with the Hudson Mountains to the north and with areas of high ground to the south are consistent with bedrock shaped by glacial erosion and deposition.

From early satellite imagery we infer that the glacier was last in contact with the highest point of the ridge in the early 1970s. A January 1973 Landsat 1 Multi-spectral Scanner picture showed a bump in the ice surface that had disappeared several years later, when nearby flow patterns had also changed (Fig. 1c). Interpreted as an ice rumple caused by contact between the ice and a topographic high on the sea floor ${ }^{22}$, the feature was situated $5 \mathrm{~km}$ inland of the point where mission 433 was turned back by the continuing rise of the seabed. Assuming the observed slope angle continued to the ridge crest, bed elevation beneath the 1973 bump could be as high as $550 \mathrm{~m}$ below sea level, 
leaving no more than $100 \mathrm{~m}$ of water between ice and seabed in January 2009. Between 1995 and 2008 the ice shelf was thinning at an accelerating rate, losing 70-80 $\mathrm{m}$ in thickness overall (ref. 5), so more gradual thinning over the preceding 20 years is consistent with the ice floating free from the highest point of the ridge over this timescale. The bump was the only point of grounding discernable in 1973, so the current phase of thinning was already underway.

Grounding line retreat from the ridge has left more than $30 \mathrm{~km}$ of previouslygrounded glacier base exposed to the warmth of the ocean. In the mid-1990s, the basal melt rate over much of this region was estimated to exceed $50 \mathrm{~m} \mathrm{yr}^{-1}$ (ref. 7). Melting must have increased since then, because the input of ice from upstream of the grounding line has increased by at least $40 \%$ as a result of the glacier's acceleration ${ }^{3}$ while the floating tongue has continued to thin ${ }^{5}$. Observations of water properties within the cavity (Fig. 4) are essential to an understanding of this increased melting and thinning. The ridge presents an obstacle to the flow of CDW towards the grounding line, with the gap above its crest limiting how rapidly inner cavity waters can be renewed. Currents driven by tides, and current shear driven by density differences will be stronger in the thinner water column over the ridge crest, leading to maxima in frictional drag and turbulent mixing, processes that limit the exchange of water across the ridge while cooling the inflow and warming the outflow. Efficient vertical heat exchange will have promoted rapid melting, thinning of the ice shelf and widening of the gap over the ridge. This in turn will have facilitated exchange between outer and inner cavity and reduced mixing between inflow and outflow, leading to increased heat transport to the inner cavity and progressively stronger melting near the grounding line.

The fuel for, and impact of, melting can be traced in the potential temperature, salinity and dissolved oxygen measurements made along the track of the AUV (Fig. 4a,b,c). The inflowing CDW is characterised by high temperature, high salinity and low 
dissolved oxygen, while the melt-laden outflow has been cooled by the extraction of latent heat, diluted by the addition of freshwater and enriched in oxygen by the dissolution of air released from bubbles in the ice ${ }^{16,17}$. Cooling and dilution have opposing effects on the seawater density, but dilution dominates and the mixtures of CDW and meltwater flow out as buoyant currents along the ice shelf base, gathered by the Coriolis force to the south. The melt-laden outflow also carries a signature of increased light attenuation (Fig. 4d), an indication of turbidity arising from suspended sediment. The strongest signal is carried by the thick melt-laden layer in the south, pointing to a sediment source in the inner cavity, although some resuspension might occur as a result of strong currents over the ridge. The most likely explanation for the bulk of the sediment load is either the discharge of sediment-laden meltwater at the grounding line or the melting of a sediment-rich layer of basal ice immediately downstream. Either way this is an indication that the rapid flow of the glacier is promoted by a deforming substrate and active basal water system, and that the processes that led to sediment deposition on the seaward slope of the ridge are ongoing.

Our findings have important implications for understanding the processes driving rapid loss of ice from this sector of West Antarctica. The observed changes on PIG, although variable in rate, with at least one period of relative stasis ${ }^{2}$ and more recent acceleration $^{3,5}$, have nevertheless been monotonic. In contrast, modelling work ${ }^{23}$ has suggested that the oceanic forcing widely held to be responsible ${ }^{8,9}$ has been characterised by seasonal, interannual and interdecadal variability rather than a longterm trend. We can now reconcile these apparently contradictory conclusions. Once the grounding line began its downslope migration from the ridge crest prior to the 1970 's, a period of rapid change was inevitable ${ }^{10}$, and since that time oceanic variability may have had relatively little influence on the rate of retreat. Thinning of the ice shelf through increased basal melting has been sustained by a positive feedback in which thinner ice allows more ocean heat over the ridge and into the growing inner cavity. 
Unless some complexity in the flow of the glacier or in its interaction with the ocean acts to stabilise the grounding line, its retreat is likely to continue for another $200 \mathrm{~km}$ until it encounters the next rise in the bed (Fig. 2c). Possible stabilising processes include convergent ice flow caused by the geometry of the main glacier channel or by the inflow of tributary glaciers, movement of basal sediment to form a new topographic pinning point ${ }^{24}$, or cessation of ice shelf thinning as widening of the gap over the ridge or thinning of the CDW layer ${ }^{23}$ weakens the topographically-controlled ocean warming in the inner cavity.

These site-specific processes notwithstanding, ice loss that extends beyond PIG and encompasses two neighbouring glacier basins ${ }^{25}$ implies a common cause, possibly related to the disappearance of a more extensive ice shelf in Pine Island Bay less than a century ago ${ }^{26}$, triggering synchronous accelerations in its three tributary glaciers. Analogous signatures of ice sheet thinning have been observed at many locations around Antarctica where outlet glaciers terminate in the ocean ${ }^{1,27}$. If these continentwide changes are driven by the same external forcing, they must all have a multidecadal, perhaps centennial, timescale, and basin-to-basin differences in the rates and spatial extent of the thinning must be associated with thresholds between fast and slow response in individual outlet glaciers.

The datasets described in this report are unique in several respects. They constitute $90 \%$ of all the data ever collected from AUV deployments beneath ice shelves and thus provide the most detailed and spatially complete set of observations from any sub-ice cavity. They are also the first data of any kind from beneath one of the rapidly-thinning ice shelves of the Amundsen Sea. They place recently-observed changes within the context of a longer-term phase of retreat and demonstrate that a threshold associated with the shape of the glacier bed had already been passed when 
those observations began. The results of this study will thus be critical in addressing urgent questions about the future evolution of PIG and its impact on global sea level.

\section{Methods}

The Autosub3 AUV (ref. 28) was deployed from the research icebreaker Nathaniel B Palmer. With respective range and depth ratings of $400 \mathrm{~km}$ and $1600 \mathrm{~m}$, the vehicle operated between launch and recovery without external guidance, collecting data along a pre-programmed track while navigating by dead reckoning relative to the seabed or the ice shelf base. The AUV was equipped with: a Seabird 911 conductivitytemperature-depth (CTD) system with integrated dissolved oxygen sensor and WetLabs transmissometer; a Kongsberg EM2000 multi-beam echosounder, pre-configured to image either ice shelf base or seabed; and both upward- and downward-looking RDI Teledyne acoustic Doppler current profilers (ADCPs). It gathered data along $877 \mathrm{~km}$ of track during 167 hours of operations, of which nearly 60\% was beneath the PIG ice shelf (Fig. 1b).

The first three forays beneath the ice (missions 428, 429 and 430) reached halfway into the cavity along parallel tracks $10 \mathrm{~km}$ apart, maintaining $100 \mathrm{~m}$ clearance from the seabed inbound and ice base outbound. Subsequent tracks were planned to extend as close to the grounding line as safely allowed, and the fourth run (mission 431) achieved $50 \mathrm{~km}$ beneath the ice before turning back when the water column thinned to less than $200 \mathrm{~m}$. At that point the AUV lost track of the rugged ice shelf basal topography, ascended into a crevasse, collided with the ice and executed avoidance manoeuvres that prompted it to abort its program and take a direct route to the recovery waypoint. After minor repairs, the final two forays were modified to focus on bottom tracking. Mission 433, following a course between those of 429 and 430, was turned back by a thinning water column after achieving only $25 \mathrm{~km}$ beneath the ice. Mission 
434 followed earlier tracks (428 and 431) for $30 \mathrm{~km}$, before working south as far as the programmed turning point, and north until the water column thinned to less than $200 \mathrm{~m}$.

1. Rignot, E. et al. Recent Antarctic ice mass loss from radar interferometry and regional climate modelling. Nature Geoscience 1, 106-110 (2008).

2. Joughin, I., Rignot, E., Rosanova, C. E., Lucchitta, B. K. \& Bohlander, J. Timing of recent accelerations of Pine Island Glacier, Antarctica. Geophys. Res. Lett. 30, 1706 (2003).

3. Rignot, E. Changes in West Antarctic ice stream dynamics observed with ALOS PALSAR data. Geophys. Res. Lett. 35, L12505 (2008).

4. Shepherd, A., Wingham, D. J., Mansley, J. A. D. \& Corr, H. F. J. Inland thinning of Pine Island Glacier, West Antarctica. Science 291, 862-864 (2001).

5. Wingham, D. J., Wallis, D. W. \& Shepherd, A. Spatial and temporal evolution of Pine Island Glacier thinning, 1995-2006. Geophys. Res. Lett. 36, L17501 (2009).

6. Shepherd, A., Wingham, D. \& Rignot, E. Warm ocean is eroding West Antarctic ice sheet. Geophys. Res. Lett. 31, L23402 (2004).

7. Rignot, E. J. Fast recession of a West Antarctic glacier. Science 281, 549-551 (1998).

8. Thomas, R. H., Rignot, E., Kanagaratnam, P., Krabill, W. \& Casassa, G. Forceperturbation analysis of Pine Island Glacier, Antarctica, suggests cause for recent acceleration. Ann. Glaciol. 39, 133-138 (2004).

9. Payne, A. J., Vieli, A., Shepherd, A. P., Wingham, D. J. \& Rignot, E. Recent dramatic thinning of largest West Antarctic ice stream triggered by oceans. Geophys. Res. Lett. 31, L23401 (2004).

10. Schoof, C. Ice sheet grounding line dynamics: steady states, stability, and hysteresis. J. Geophys. Res. 112, F03S28 (2007). 
11. Mercer, J. H. West Antarctic ice sheet and $\mathrm{CO}_{2}$ greenhouse effect: a threat of disaster. Nature 271, 321-325 (1978).

12. Oppenheimer, M. Global warming and the stability of the West Antarctic ice sheet. Nature 393, 325-332 (1998).

13. Nitsche, F. O., Jacobs, S. S., Larter, R. D. \& Gohl, K. Bathymetry of the Amundsen Sea continental shelf: implications for geology, oceanography, and glaciology.

Geochem. Geophys. Geosyst. 8, Q10009 (2007).

14. Walker, D. P. et al. Oceanic heat transport onto the Amundsen Sea shelf through a submarine glacial trough. Geophys. Res. Lett. 34, L02602 (2007).

15. Jacobs, S. S., Hellmer, H. H. \& Jenkins A. Antarctic ice sheet melting in the southeast Pacific. Geophys. Res. Lett. 23, 957-960 (1996).

16. Hellmer, H. H., Jacobs, S. S. \& Jenkins A. Oceanic erosion of a floating Antarctic glacier in the Amundsen Sea. Antarct. Res. Ser. 75, 83-99 (1998).

17. Jenkins, A. The impact of melting ice on ocean waters. J. Phys. Oceanogr. 29, 2370-2381 (1999).

18. Jenkins, A., Vaughan, D. G., Jacobs, S. S., Hellmer, H. H. \& Keys, J. R. Glaciological and oceanographic evidence of high melt rates beneath Pine Island Glacier, West Antarctica. J. Glaciol. 43, 114-121 (1997).

19. Dupont, T. K. \& Alley, R. Assessment of the importance of ice-shelf buttressing to ice-sheet flow. Geophys. Res. Lett. 32, L04503 (2005).

20. Goldberg, D., Holland, D. M. \& Schoof, C. Grounding line movement and ice shelf buttressing in marine ice sheets. J. Geophys. Res. 114, F04026 (2009).

21. Lowe, A. L. \& Anderson, J. B. Evidence for abundant subglacial meltwater beneath the paleo-ice sheet in Pine Island Bay, Antarctica. J. Glaciol. 49, 125-138 (2003). 
22. Swithinbank, C. et al. Coastal-change and glaciological map of the Eights Coast area, Antarctica: 1972-2001 (Geol. Invest. Ser. Map I-2600-E, USGS, Denver, 2004).

23. Thoma, M., Jenkins, A., Holland, D. \& Jacobs, S. Modelling Circumpolar Deep Water intrusions on the Amundsen Sea continental shelf, Antarctica. Geophys. Res. Lett. 35, L18602 (2008).

24. Alley, R. B., Anandakrishnan, S., Dupont, T. K., Parizek, B. R. \& Pollard, D. Effect of sedimentation on ice-sheet grounding-line stability. Science 315, 1838-1841 (2007).

25. Shepherd, A., Wingham, D. J. \& Mansley, J. A. D. Inland thinning of the Amundsen Sea sector, West Antarctica. Geophys. Res. Lett. 29, 1364 (2002).

26. Kellogg, T. B. \& Kellogg, D. E. Recent glacial history and rapid ice stream retreat in the Amundsen Sea. J.Geophys. Res. 92, 8859-8864 (1987).

27. Pritchard, H. D., Arthern, R. J., Vaughan, D. G. \& Edwards, L. A. Extensive dynamic thinning on the margins of the Greenland and Antarctic ice sheets. Nature 461, 971-975 (2009).

28. McPhail, S. D. et al. Exploring beneath the PIG Ice Shelf with the Autosub3 AUV. Oceans 09, doi: 10.1109/OCEANSE.2009.5278170 (2009).

29. Holt, J. W. et al. New boundary conditions for the West Antarctic ice sheet: subglacial topography of the Thwaites and Smith glacier catchments. Geophys. Res. Lett. 33, L09502 (2006).

30. Vaughan, D. G. et al. New boundary conditions for the West Antarctic ice sheet: subglacial topography beneath Pine Island Glacier. Geophys. Res. Lett. 33, L09501 (2006).

Acknowledgements We thank the Captain and crew of Nathaniel B Palmer and NBP09-01 cruise participants for assistance with the AUV operations. This work was funded by the UK Natural Environment Research Council (NE/G001367/1) and the US National Science Foundation 
(ANT0632282). Rory Howlett, Gwyn Griffiths, Keith Nicholls and Sarah Jenkins commented on the manuscript.

Author Contributions A.J. and S.S.J. proposed the research. A.J., P.D. and S.D.M. planned the AUV missions. S.D.M., J.R.P., A.T.W. and D.W. prepared and programmed the AUV. P.D., S.D.M. and J.R.P. processed the data. A.J., P.D. and S.S.J. analysed the results. A.J. wrote the text. A.J. and P.D. prepared the figures. All authors read and commented on the paper.

Author Information Reprints and permissions information is available at npg.nature.com/reprintsandpermissions. Correspondence and requests for materials should be addressed to A.J. (ajen@bas.ac.uk). 
Figure 1. Map and satellite imagery of the study area. (a) Map of Antarctica (inset) and enlargement of the coastal zone around Pine Island Bay, showing grounded ice sheet (dark grey) and floating ice shelves (light grey). The small box over Pine Island Glacier (PIG) indicates the area covered by (b), while the bold line indicates the cross-section in Fig. 2c. (b) Modis image of PIG obtained on $28^{\text {th }}$ December 2008 showing tracks followed by Autosub3 (white, labelled with mission number) and the grounding line (bold, white) as mapped in 1996 (ref. 7). The black box and circle indicate the areas covered by, and circled within, (c). (c) Evolution of surface features on the PIG ice shelf. The bump (circled) in the 1973 image is smaller in 1975 and entirely absent in 1982, to be replaced by more complex topography in recent years.

Figure 2. Configuration of the ocean cavity beneath the PIG ice shelf. (a) Seabed depth derived from AUV pressure and downward-looking ADCP range data. Beyond the boundaries of the floating ice (bold) additional bathymetric data come from ship sonar ${ }^{13}$ and airborne $\operatorname{radar}^{29,30}$ sounding. Interpolation has been constrained in data gaps (cross-hatched) to ensure that the seabed is deeper than the ice draft measured by radar. Thin white lines show the AUV tracks. Magenta boxes indicate the sections enlarged in Fig 3. (b) Water column thickness calculated as the difference between seabed depth (a) and ice draft derived by combining AUV pressure and upward- looking ADCP range data with radar soundings ${ }^{29,30}$. (c) Profiles of ice base (magenta) and seabed (black) elevation measured along the tracks of missions 428, 431 and 434 (Fig 1b), combined with ice surface and bed elevation data (grey) measured by $\operatorname{radar}^{29,30}$ along the same track and extended inland along the axis of the main glacier channel (Fig. 1a). 
Figure 3. Multi-beam echosounder imagery of the seabed ridge beneath the PIG ice shelf. Seabed topography mapped during mission 434 (Fig 1b) (a) in the outer cavity (b) on the seaward slope of the ridge and (c) on the ridge crest. Locations of the individual boxes are shown in Fig. 2a. The data swath is $300 \mathrm{~m}$ wide in all cases. Arrows give an indication of the present direction of ice flow, inferred from Fig. 1b, and red lines an indication of relative horizontal scale.

Figure 4. Seawater properties observed in the ocean cavity beneath the PIG ice shelf. (a) Potential temperature $\left({ }^{\circ} \mathrm{C}\right)$, (b) salinity, (c) dissolved oxygen concentration $(\mathrm{ml} / \mathrm{l})$ and $(\mathbf{d})$ light attenuation $\left(\mathrm{m}^{-1}\right)$ as measured by Autosub3 along the tracks of missions 428,431 and 434 (Fig 1b). Profiles of ice surface, ice base and seabed elevation are plotted as in Fig 2c. 

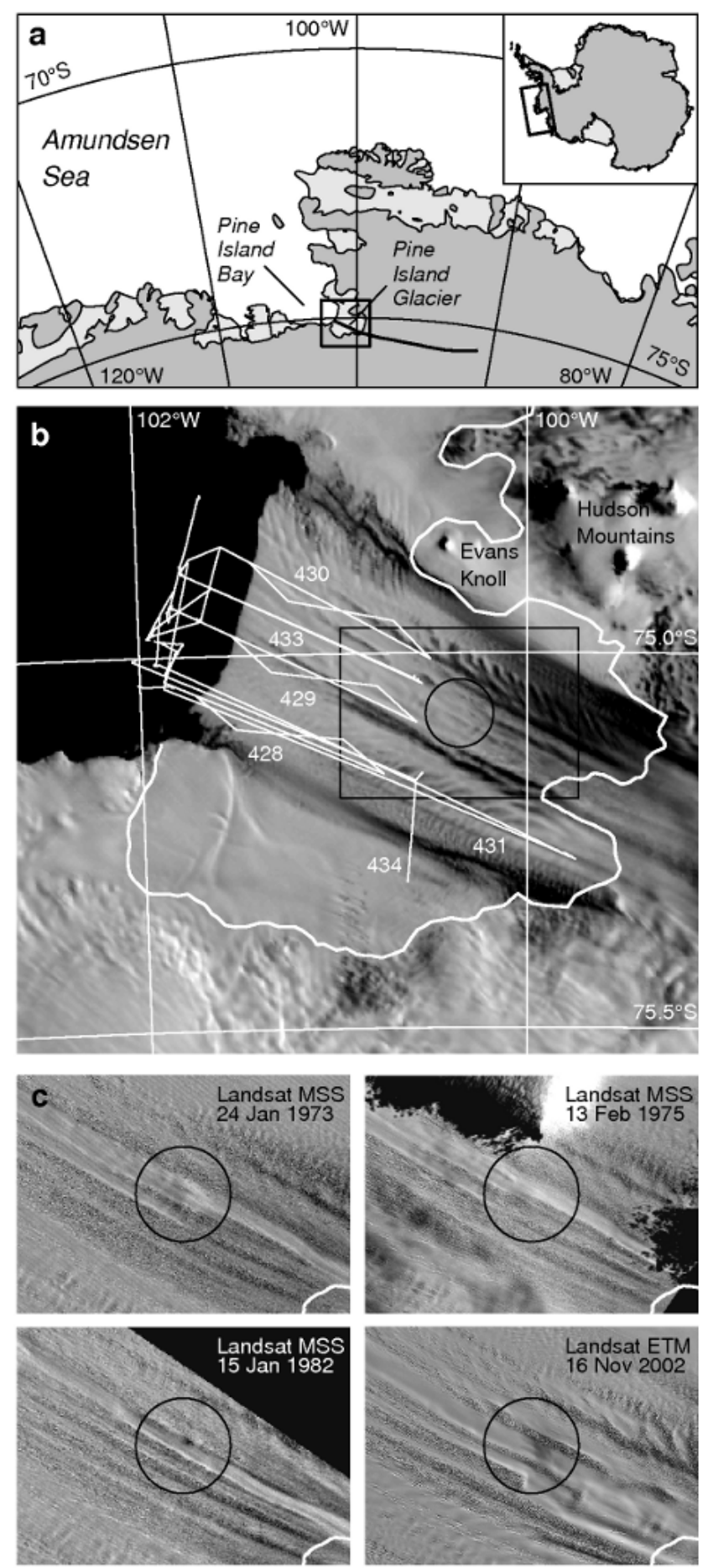

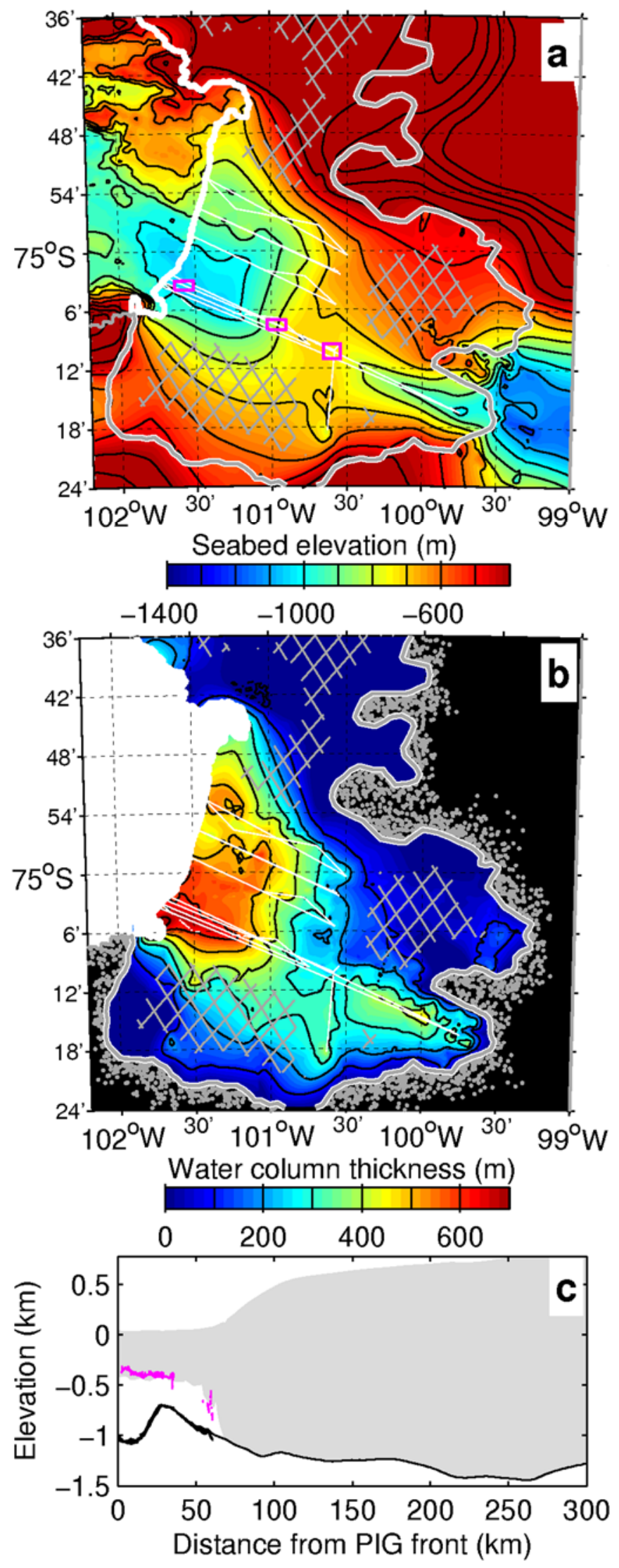

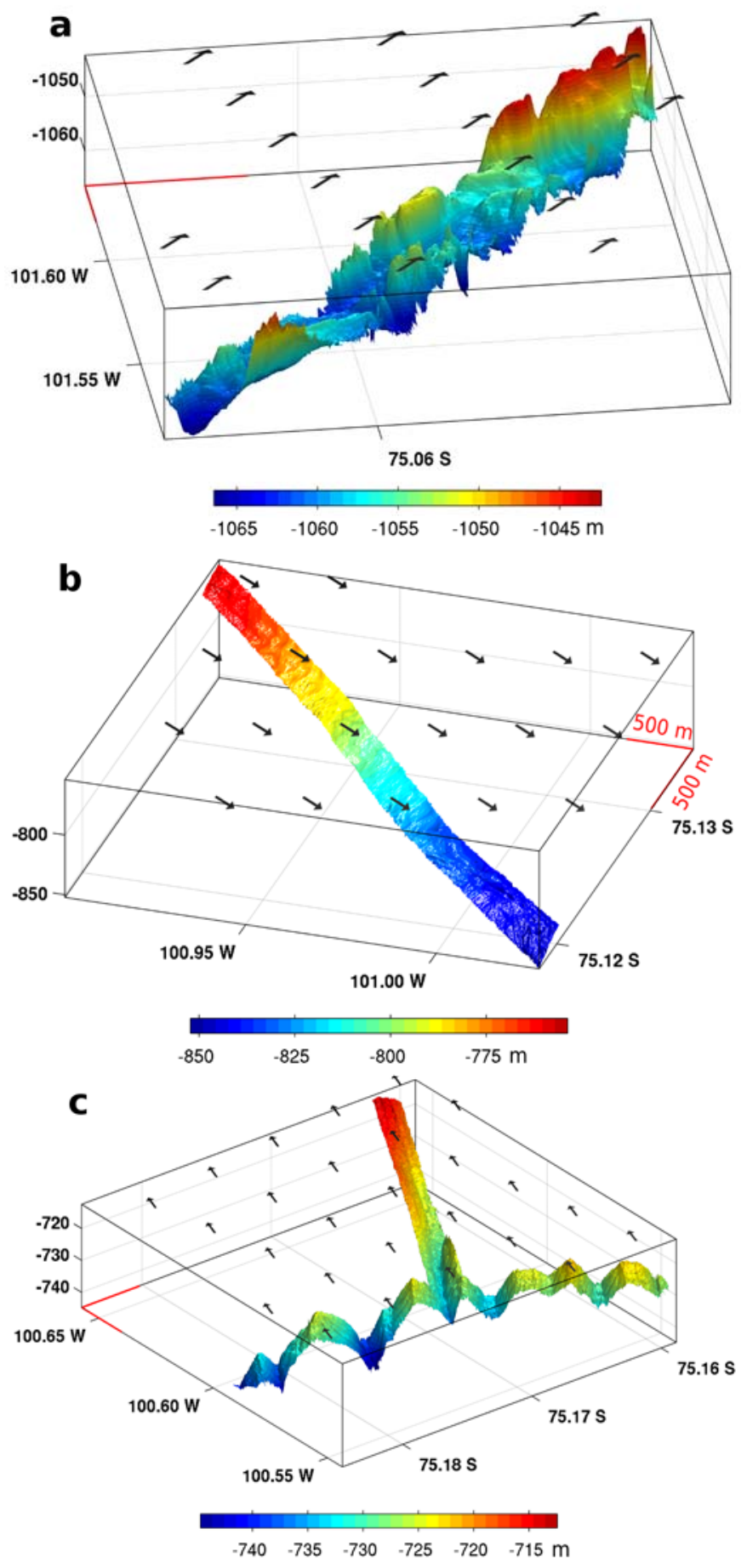

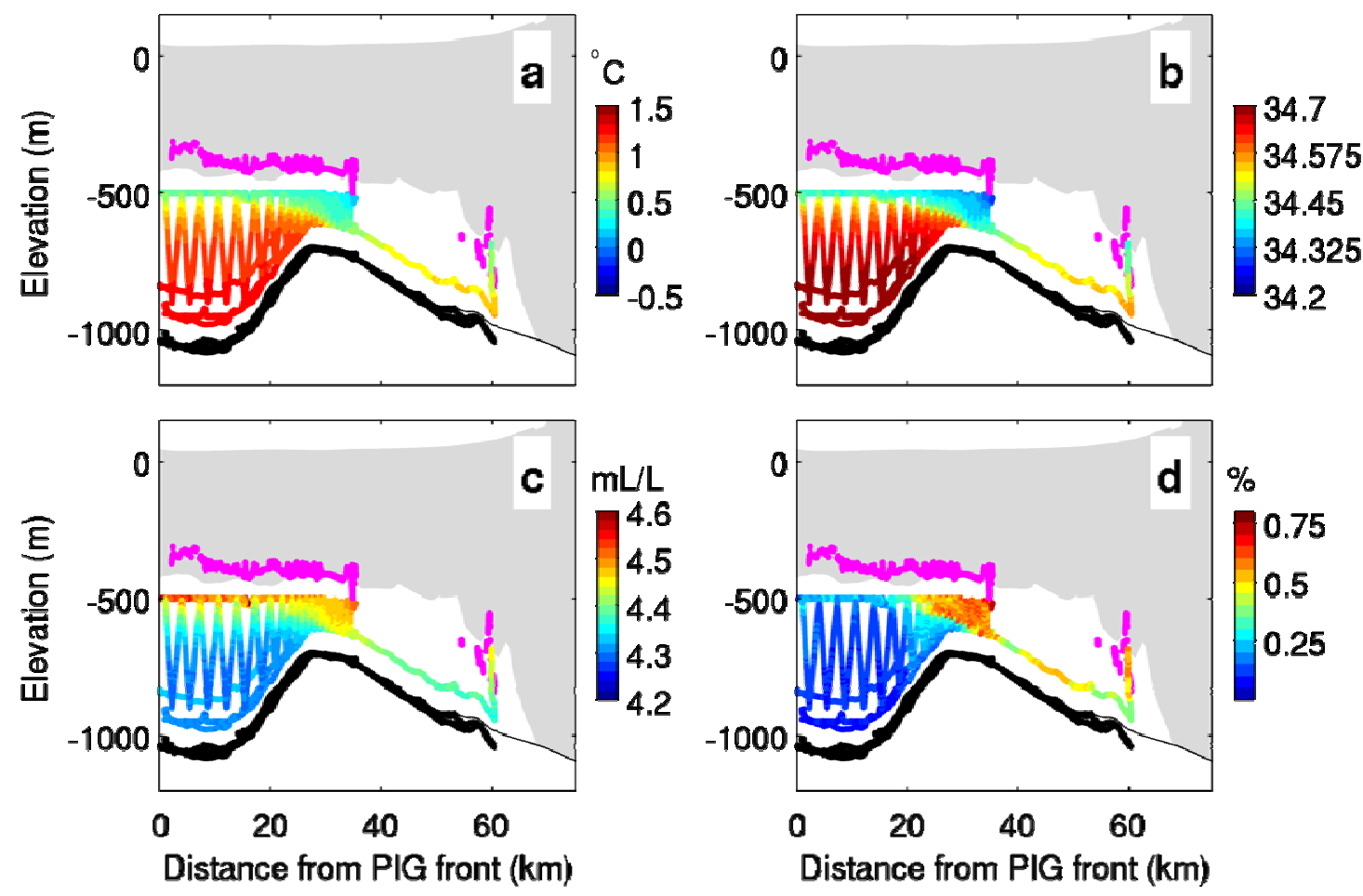